\title{
Intra-operative intravascular effect of the difference in colloid solutions during acute normovolemic hemodilution
}

\author{
Yoko Midorikawa, Junichi Saito* (D, Masato Kitayama, Kentaro Toyooka and Kazuyoshi Hirota
}

\begin{abstract}
Background: Acute normovolemic hemodilution (ANH) is used to reduce the risk of peri-operative allogeneic blood transfusion. Although crystalloid and/or colloid solutions have been used for volume replacement during $\mathrm{ANH}$, no studies have examined the differences among solutions on the volume status, electrolytes, acid-base balance, and hemodynamic status during surgery with ANH.
\end{abstract}

Methods: We retrospectively compared the effect of Ringer's lactate with 3\% dextran-40 (Saviosol ${ }^{\circledR}$, DEX group) and $6 \%$ hydroxyethyl starch 130/0.4 in 0.9\% sodium chloride (Voluven ${ }^{\oplus}$, HES group) on blood hemoglobin serum electrolytes and estimated blood volume before induction of anesthesia (baseline), after ANH and after blood transfusion following surgery in patients undergoing open gynecological surgery ( $n=111$ and 67, respectively). The primary outcomes were the changes in hemoglobin and electrolytes after ANH.

Results: There were no differences in hemoglobin or electrolytes between the two groups at baseline. Postoperative hemoglobin was significantly higher $(11.0 \pm 1.5 \mathrm{~g} / \mathrm{dL}$ vs $9.9 \pm 1.3 \mathrm{~g} / \mathrm{dL}$ ) (mean $\pm \mathrm{SD}$ ) in the DEX group than in the HES group $(p=0.03)$. Postoperative potassium was significantly decreased from the baseline both in the DEX group $(137.9 \pm 2.5 \mathrm{mmol} / \mathrm{L}$ vs $136.3 \pm 2.7 \mathrm{mmol} / \mathrm{L})$ and in the HES group $(138.3 \pm 2.0 \mathrm{mmol} / \mathrm{L}$ vs $137.8 \pm 2.5 \mathrm{mmol} / \mathrm{L})(p<0.001$ for both); however, it was significantly higher than in the DEX group after surgery $(p$ $<0.001$ ). Estimated blood volume after surgery was significantly increased after ANH in both groups; however, it was larger in the HES group than in the DEX group.

Conclusions: Postoperative hemoglobin and potassium were significantly higher, and estimated blood volume was significantly smaller in the DEX than in the HES group.

Keywords: Acute normovolemic hemodilution, Colloid, Hydroxylethyl starch, Dextran, Gynecological cancer, Blood volume

\section{Introduction}

Acute normovolemic hemodilution (ANH) is one of the autologous blood transfusion techniques that are used to reduce the risk of peri-operative allogeneic blood transfusion in both cardiac surgery $[1,2]$ and non-cardiac surgery [3-5]. The coronavirus disease 2019 (COVID19) pandemic has had a negative impact on blood

\footnotetext{
*Correspondence: saitoj@hirosaki-u.ac.jp

Department of Anesthesiology, Hirosaki University Graduate School of Medicine, Zaifu-cho 5, Hirosaki 036-8562, Japan
}

donations, resulting in an allogeneic blood supply shortage and cancelations of surgery worldwide [6, 7]. In this situation, the use of ANH can be a key strategy to reduce the demand for allogeneic transfusions [8].

A rapid infusion of a crystalloid and/or colloid solution is necessary to maintain euvolemia during acute hemodilution. Compared to crystalloid solutions, colloid solutions, i.e., those containing albumin, dextran, gelatin, and hydroxyethyl starch, provide some advantages for maintaining a patient's hemodynamic state during acute blood loss $[9,10]$. In addition to the differences in types

\section{Springer Open}

(0) The Author(s). 2021 Open Access This article is licensed under a Creative Commons Attribution 4.0 International License, which permits use, sharing, adaptation, distribution and reproduction in any medium or format, as long as you give appropriate credit to the original author(s) and the source, provide a link to the Creative Commons licence, and indicate if changes were made. The images or other third party material in this article are included in the article's Creative Commons licence, unless indicated otherwise in a credit line to the material. If material is not included in the article's Creative Commons licence and your intended use is not permitted by statutory regulation or exceeds the permitted use, you will need to obtain permission directly from the copyright holder. To view a copy of this licence, visit http://creativecommons.org/licenses/by/4.0/. 
of colloid, the composition of the fluids differs among the colloid solutions, depending on whether the solution is Ringer's-based or saline-based.

Ringer's lactate with 3\% dextran-40 (Saviosol'; Otsuka Pharmaceutical Factory, Naruto, Japan) had been used until 2014; then, it was replaced with 6\% hydroxyethyl starch $130 / 0.4$ in $0.9 \%$ sodium chloride (Voluven; Otsuka Pharmaceutical Factory). To the best of our knowledge, there has been no investigation on the impacts of colloid solutions in patients receiving ANH. We compared the effect of these two colloid solutions on the volume status, electrolytes, acid-base balance, and hemodynamic status during surgery. We conducted the present retrospective study to assess the impact of colloid solutions on the volume status, electrolytes, acidbase balance, and hemodynamic status during ANH.

\section{Methods}

The study adheres to the STROBE statement. The retrospective study design and protocol were approved by the Ethics Committee of Hirosaki University Graduate School of Medicine and publicized on our hospital homepage (2021-039). As the study was retrospective, the requirement of patients' written informed consent was waived by the Ethics Committee. The patient characteristics and peri-operative data were collected from anesthetic and medical records of patients with gynecological cancer ( $\geq 20$ years old) who received ANH during open abdominal surgery at Hirosaki University Hospital during the period from April 1, 2013, to March 31, 2016. Patients who did not receive ANH or were infused with both Saviosol ${ }^{\circ}$ and Voluven ${ }^{\circ}$ during surgery were excluded from the study. We divided the patients into two groups based on the colloid solutions: the Saviosol $^{\circ}$ (DEX) group and the Voluven ${ }^{\circ}$ (HES) group.

\section{Data collection}

We collected the following data from the patients' medical records: age, height, body weight, body mass index (BMI), and the use of peri-operative allogeneic blood transfusion (red blood cells, fresh frozen plasma, and platelet concentration until postoperative day [POD] 3). The following data were collected from the patients' anesthesia records: the American Society of Anesthesiologists-Physical Status (ASA-PS); the amounts of ephedrine and/or phenylephrine administered; the amount of ANH blood; the intra-operative total fluid volume of crystalloid and colloid, i.e., Voluven ${ }^{\circ}$ and Saviosol ${ }^{\circ}$; the intra-operative urine out; the intraoperative estimated blood loss; and the durations of surgery and anesthesia. Peri-operative laboratory values including the hemoglobin concentration $(\mathrm{Hb})$, platelet count, serum sodium $(\mathrm{Na})$, potassium $(\mathrm{K})$, chloride $(\mathrm{Cl})$, and base excess $(\mathrm{BE})$ were obtained at three time points: before the induction of anesthesia, after acute hemodilution, and after the surgery (after a re-transfusion of ANH blood) in the post-anesthesia care unit.

We also collected the data of the patients' perioperative kidney function (serum creatinine [sCre] and the estimated glomerular filtration rate [eGFR]) within 14 days before surgery and on POD-1 from the electronic medical records. The primary outcomes were the changes in $\mathrm{Hb}$ and changes in electrolytes during $\mathrm{ANH}$.

\section{Calculation of blood volume and changes in blood volume}

Blood volume (BV) was calculated using the formula [11]:

$$
\begin{aligned}
\mathrm{BV}(\mathrm{dL})= & \left(0.0003561 \times \text { height }^{3}(\mathrm{~cm})\right. \\
& +[33.08 \times \text { body weight }(\mathrm{kg})+183]) / 100
\end{aligned}
$$

The patient's BV after surgery was calculated by first estimating the total $\mathrm{Hb}$ mass in the circulation at baseline "Hbmass $(0)$ " as being equal to the product of $\mathrm{BV}(0)$ and the $\mathrm{Hb}$ concentration at baseline, " $\mathrm{Hb}(0)$." Losses from $\mathrm{Hb}$ mass were then subtracted for measurement, and the $\mathrm{BV}(1)$ was obtained by dividing this difference by a freshly taken $\mathrm{Hb}$ value after surgery $[12,13]$.

$$
\begin{aligned}
& \operatorname{Hbmass}(0)=\mathrm{BV}(0) \times \mathrm{Hb}(0) \\
& \operatorname{Hbmass}(\text { loss })=\text { blood loss } \times \mathrm{Hb}(1) \\
& \mathrm{BV}(1)=[\operatorname{Hbmass}(0)-\operatorname{Hbmass}(\text { loss })] / \mathrm{Hb}(1) \\
& \text { Changes in } \mathrm{BV}=\mathrm{BV}(1)-\mathrm{BV}(0)
\end{aligned}
$$

\section{General anesthesia and ANH}

All open abdominal gynecological surgeries were managed under total intravenous anesthesia: propofol, ketamine, remifentanil and/or fentanyl, and rocuronium. ANH was conducted in patients who were at risk of a blood loss of $\geq 500 \mathrm{~mL}$ during surgery, at the request of the gynecological surgeon.

Blood withdrawal from the patients was started just after induction of anesthesia and before skin incision. The whole blood from a central venous line was collected into standard blood collection bags containing a citrate phosphate dextrose solution. To maintain the patient's euvolemia and mean arterial pressure $\geq 60$ $\mathrm{mmHg}$, the withdrawn whole blood was replaced by the same volume of colloid solution $\left(\right.$ Voluven $^{\circ}$ or Saviosol ${ }^{\circ}$ ). To maintain mean arterial pressure $\geq 60 \mathrm{mmHg}$, ephedrine and/or phenylephrine were administered during blood withdrawal. The withdrawn blood volume for ANH was targeted at $400-800 \mathrm{~mL}$ and decided by the attending anesthesiologist and supervisor of the 
operating theater to prevent $\mathrm{Hb}<8.0 \mathrm{~g} / \mathrm{dL}$ after acute hemodilution. ANH procedure took about 20 to $25 \mathrm{~min}$ to collect $800 \mathrm{~mL}$ of blood. ANH blood bags were shaken $60-80 \mathrm{rpm}$ in the room temperature. Subsequently, all patients received acetate Ringer's solution and/or colloid solution during anesthesia. When a specimen was removed or surgical hemostasis was performed, all of the collected ANH blood was reinfused to the patient in the operating theater.

\section{Statistical analyses}

We used the D'Agostino and Pearson normality test to determine whether all variables showed a Gaussian distribution. Continuous data are presented as the mean \pm standard deviation (SD) or the median [interquartile range, IQR]. Categorical data are presented as the number (\%). Student's $t$-test or the Mann-Whitney $U$-test was used for analyzing continuous variables, and the Chi-squared test or Fisher's exact test was used for analyzing categorical variables. We conducted a repeated two-way analysis of variance (ANOVA) with Tukey's multiple comparisons tests to evaluate the changes in all variables in the peri-operative period. A repeated twoway ANOVA with Sidak's multiple comparisons test was conducted to assess the difference in each time point between the two groups. Probability $(p)$-values $<0.05$ were considered significant. All reported $p$-values are twotailed. Statistical analyses were performed using GraphPad Prism 7.02 (GraphPad Software, San Diego, CA, USA).

No prior sample size calculation was performed in this study. However, our sample size (111 vs 67 ) had $99.1 \%$ power to detect $300 \mathrm{~mL}$ absolute difference in BV after surgery between the DEX and the HES group at the 0.05 level. Sample size calculation was performed using EZR software ver. 1.37 (Saitama Medical Center, Jichi Medical University, Saitama, Japan).

\section{Results}

Of the 189 patients initially included, 11 were excluded from the analysis because both Saviosol ${ }^{\circ}$ and Voluven ${ }^{\circ}$ were infused during surgery. Subsequently, data from 178 patients (DEX group, $n=111$ and HES group, $n=$ 67) were analyzed. There were no differences in the patients' profiles, volume of ANH, estimated blood loss, allogeneic transfusion, and duration of surgery (Table 1).

\section{Volume of infusion, hemoglobin concentration, and estimated blood volume}

The volume of colloid solution was comparable between the two groups. On the other hand, both the volume of crystalloid and the total volume of colloid and crystalloid solution were significantly larger in the DEX than in the HES group ( $p<0.001$ for both, Table 1). Hemoglobin concentration significantly decreased after ANH from the baseline, which was increased at the end of surgery in both groups. However, it was significantly higher in the DEX group than in the HES group after surgery ( $p=$ 0.03 , Table 2). Estimated blood volume was significantly increased after ANH compared with baseline $(p<0.01)$ and decreased after surgery in both groups (Fig. 1c). The BV after surgery in the DEX group was comparable to the baseline, whereas it was significantly larger than baseline in the HES group $(p<0.01)$, and significantly larger than in the DEX group $(p<0.01)$. Platelet count was significantly decreased after ANH and remained unchanged in both groups, and there were no differences between the two groups during the study period.

\section{Electrolytes}

Serum $\mathrm{Na}$ significantly decreased after $\mathrm{ANH}$ and after surgery compared with the baseline in the DEX group. On the other hand, serum $\mathrm{Na}$ unchanged after ANH, and decreased after surgery compared before ANH in the HES group. Serum Na in the DEX group was significantly lower than the HES group after ANH and surgery $(p<0.001$ for both, Table 2$)$. Serum K was significantly decreased after ANH and after surgery compared with baseline in both groups $(p<0.001$ for both, Table 2$)$, and there were no differences between the two groups during the study period. Serum chloride was significantly increased in both group after ANH and after surgery compared with baseline in both groups $(p<0.01$ for both), but it was significantly higher in the HES group than in the DEX group $(p<0.01$, Table 2$)$.

\section{Base excess and lactate}

$\mathrm{BE}$ was significantly higher in the DEX group compared with the HES group at baseline $(p<0.001$, Table 2$)$. BE significantly decreased after ANH and after surgery. It was significantly higher in the DEX group compared with the HES group $(p<0.001)$. Serum lactate was similar between the groups at baseline, which was significantly increased after ANH and decreased after surgery in the DEX group; inversely, it was significantly decreased after $\mathrm{ANH}$ and increased after surgery in the HES group. Serum lactate was significantly higher in the DEX group than in the HES group after ANH and after surgery ( $p<0.001$ for both).

\section{Vasoactive drugs}

The rate and amounts of vasoactive drugs (ephedrine and phenylephrine) used during surgery were comparable between the two groups.

\section{Peri-operative kidney function}

As summarized in Table 3, the mean pre-operative sCre and eGFR values were comparable between the two 
Table 1 The patients' characteristics and intra-operative data

\begin{tabular}{|c|c|c|c|}
\hline & HES, $n=67$ & Dex, $n=111$ & $p$-value \\
\hline Age, years & $56(12)$ & $54(13)$ & 0.443 \\
\hline Height, cm & $154.8(4.7)$ & $155.0(6.0)$ & 0.598 \\
\hline Body weight, kg & $57.3(11.9)$ & $60.0(13.6)$ & 0.182 \\
\hline BMI & $24.0(5.1)$ & $25.0(5.6)$ & 0.259 \\
\hline \multicolumn{4}{|l|}{ ASA-PS } \\
\hline 1 & $4(6.0)$ & $7(6.3)$ & \multirow[t]{3}{*}{0.899} \\
\hline 2 & $56(83.6)$ & 95 (85.6) & \\
\hline 3 & $7(10.4)$ & $9(8.1)$ & \\
\hline \multicolumn{4}{|l|}{ Diagnosis } \\
\hline Ovarian cancer, $n(\%)$ & $11(16.4)$ & $17(15.3)$ & \multirow[t]{4}{*}{0.724} \\
\hline Uterine body cancer, $n(\%)$ & $40(59.7)$ & $61(55.0)$ & \\
\hline Cervical cancer, $n(\%)$ & $12(17.9)$ & $27(24.3)$ & \\
\hline Others, $n(\%)$ & $4(6.0)$ & $6(5.4)$ & \\
\hline \multicolumn{4}{|l|}{ Amount of ANH } \\
\hline $400-599 \mathrm{~mL}$ & $6(9.0)$ & $8(7.2)$ & \multirow[t]{3}{*}{0.654} \\
\hline 600-799 mL & $5(7.5)$ & $6(5.4)$ & \\
\hline$\geq 800 \mathrm{~mL}$ & $56(83.6)$ & $97(87.4)$ & \\
\hline \multicolumn{4}{|l|}{ Anesthetics } \\
\hline PRK & $11(16.4)$ & $17(15.3)$ & \multirow[t]{2}{*}{0.835} \\
\hline PFK & $56(83.6)$ & $94(84.7)$ & \\
\hline Total fluid infusion & $2400(2000,2700)$ & $2700(2300,3250)$ & $<0.001$ \\
\hline Crystalloid & $1500(1000,1813)$ & $1700(1350,2350)$ & $<0.001$ \\
\hline Colloid & $1000(1000,1000)$ & $1000(1000,1000)$ & 0.718 \\
\hline $\mathrm{RBC}$ & $2(3.0)$ & $1(0.9)$ & 0.557 \\
\hline FFP & $0(0)$ & $0(0)$ & 1.000 \\
\hline PC & $0(0)$ & $0(0)$ & 1.000 \\
\hline Estimated blood loss, g & $430(260,705)$ & $445(200,655)$ & 0.724 \\
\hline Urine out, mL & $185(129,300)$ & $223(133,350)$ & 0.278 \\
\hline Duration of surgery, min & $191(53)$ & $200(56)$ & 0.310 \\
\hline Duration of anesthesia, min & $253(58)$ & $266(61)$ & 0.149 \\
\hline
\end{tabular}

The data are mean (SD) or median (25\%, 75\%). ANH acute normovolemic hemodilution; ASA-PS American Society of Anesthesiologists-Physical Status; BMI body mass index; Dex dextran; FFP fresh frozen plasma; HES hydroxylethyl starch; PC platelet concentrates; PFK propofol, fentanyl, ketamine; PRK propofol, remifentanil, ketamine; $R B C$ red blood cells

groups $(p=0.866)$. On POD-1, the mean sCre values were significantly decreased $(p<0.001)$ and the mean eGFR values were significantly increased $(p<0.001)$. These values were comparable between the two groups $(p=0.636)$.

\section{Discussion}

The results of our retrospective analyses revealed that the difference in colloid solutions during ANH had significant impacts on the patients' volume status, electrolytes, and acid-base balance during surgery.

Hemoglobin levels after surgery in the DEX group was significantly higher than in the HES group, despite lager volume of fluids administered in the DEX group than in the HES group. This would result from the different effect between DEX and HES on plasma volume. HES remained in the blood vessels longer than DEX because of its longer half-life, which was supported by increased blood volume in the HES group after surgery. The product monographs of Saviosol ${ }^{\circ}$ and Voluven ${ }^{\circ}$ hold that the expansion effect lasts for 2-3 and 4-6 h, respectively. The turnover of HES based on weight/volume measurements identified the elimination half-life (T1/2) of $12.1 \mathrm{~h}$ [14], which is longer than that of Dextran 40 (elimination T1/2 $10 \mathrm{~h}$ ) [15]. Another study revealed that when Ringer's acetate was infused after HES, the elimination 
Table 2 Changes in variables during surgery

\begin{tabular}{|c|c|c|c|c|c|c|}
\hline & & Baseline & After ANH & After surgery & $F$ & $p$-value \\
\hline \multirow[t]{2}{*}{$\mathrm{Hb}, \mathrm{g} / \mathrm{dL}$} & DEX & $12.5 \pm 1.1$ & $9.4 \pm 1.5^{*}$ & $11.0 \pm 1.5^{* 5 \#}$ & 3.520 & 0.0307 \\
\hline & HES & $11.9 \pm 0.9$ & $9.0 \pm 2.7^{*}$ & $9.9 \pm 1.3^{* 5}$ & & \\
\hline \multirow[t]{2}{*}{$\mathrm{Plt}, 10^{4} / \mathrm{\mu L}$} & DEX & $24.5 \pm 6.6$ & $19.7 \pm 6.0^{*}$ & $19.9 \pm 6.1^{*}$ & 0.526 & 0.5913 \\
\hline & HES & $22.6 \pm 6.4$ & $18.4 \pm 5.2^{*}$ & $18.3 \pm 5.0^{*}$ & & \\
\hline \multirow[t]{2}{*}{$\mathrm{Na}, \mathrm{mmol} / \mathrm{L}$} & DEX & $137.9 \pm 2.5$ & $137.0 \pm 2.2^{* \#}$ & $136.3 \pm 2.7^{* \$ \#}$ & 7.962 & 0.0004 \\
\hline & HES & $138.3 \pm 2.0$ & $138.7 \pm 2.2$ & $137.8 \pm 2.5^{\S}$ & & \\
\hline \multirow[t]{2}{*}{$\mathrm{K}, \mathrm{mmol} / \mathrm{L}$} & DEX & $3.7 \pm 0.2$ & $3.5 \pm 0.3^{*}$ & $3.7 \pm 0.4^{\S}$ & 1.244 & 0.2896 \\
\hline & HES & $3.7 \pm 0.2$ & $3.4 \pm 0.2^{*}$ & $3.6 \pm 0.3^{\S}$ & & \\
\hline \multirow[t]{2}{*}{$\mathrm{Cl}, \mathrm{mmol} / \mathrm{L}$} & DEX & $107.6 \pm 2.3$ & $109.8 \pm 2.3^{* \#}$ & $109.0 \pm 3.0^{* 5 \#}$ & 22.56 & $<0.0001$ \\
\hline & HES & $107.7 \pm 2.0$ & $112.3 \pm 2.1^{*}$ & $111.0 \pm 2.4^{* S}$ & & \\
\hline \multirow[t]{2}{*}{$\mathrm{BE}, \mathrm{mg} / \mathrm{dL}$} & DEX & $1.8 \pm 1.7$ & $0.6 \pm 1.6^{* \#}$ & $0.2 \pm 1.7^{* \#}$ & 7.100 & 0.0010 \\
\hline & HES & $0.8 \pm 1.8$ & $-1.2 \pm 1.7^{*}$ & $-1.3 \pm 1.6^{*}$ & & \\
\hline \multirow[t]{2}{*}{$\mathrm{Lac}, \mathrm{mmol} / \mathrm{L}$} & DEX & $0.8 \pm 0.2$ & $1.2 \pm 0.5^{* \#}$ & $1.0 \pm 0.5^{* 5 \#}$ & 23.03 & $<0.0001$ \\
\hline & HES & $0.7 \pm 0.2$ & $0.6 \pm 0.2^{* \#}$ & $0.8 \pm 0.5^{\S \#}$ & & \\
\hline
\end{tabular}

The data are mean \pm SD

${ }^{*} p<0.01$ vs. baseline, ${ }^{\S} p<0.01$ vs. after ANH, ${ }^{*} p<0.01$ vs. HES

$D E X$ dextran, HES hydroxyethyl starch, $B E$ base excess, $C l$ chloride, $H b$ hemoglobin, $K$ potassium, Lac lactate, Na sodium, Plt platelet count

half-life of acetate Ringer's solution was five times longer compared to when acetate Ringer's solution was infused alone (497 min vs. $88 \mathrm{~min}, p<0.001$ ) [16]. In addition to the direct expansion effect of HES, an interaction with Ringer's solution might have contributed to our present results.
In both the present DEX and HES groups, the BV after hemodilution increased; the increases were similar between the two groups. The increases in BV in the two groups were greater than expected. The explanation of this phenomenon is that a decrease in blood pressure during the induction of anesthesia increased the plasma

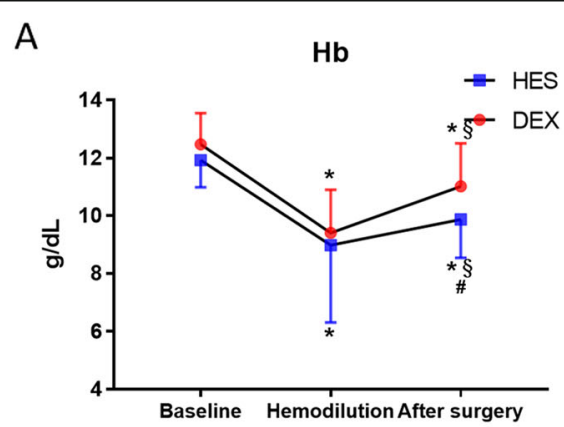

C

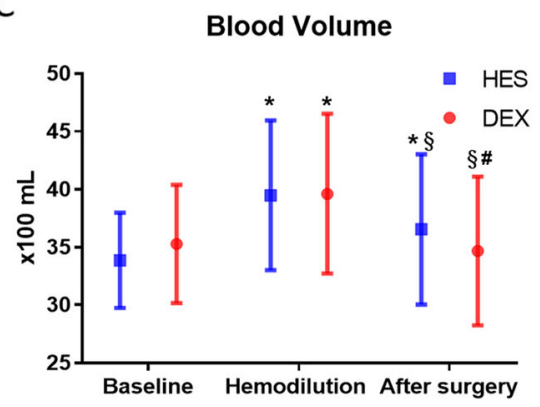

B

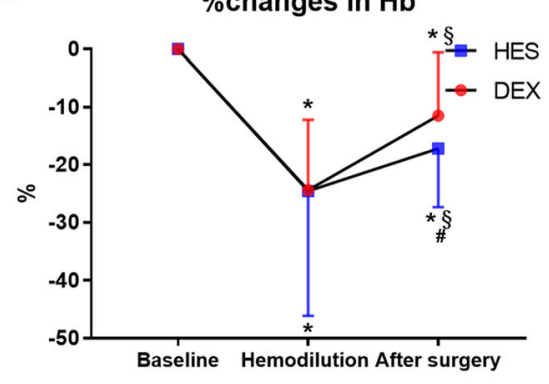

D

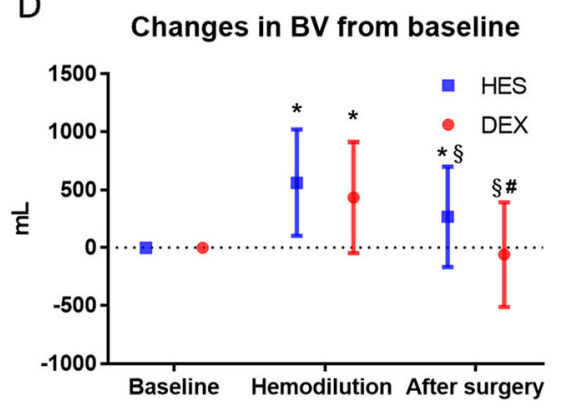

Fig. 1 Difference in hemoglobin concentration and blood volume between the HES group and the DEX group. A Changes in hemoglobin concentration. B \%Changes in hemoglobin concentration. C Changes in blood volume. D Changes in blood volume from the baseline value; HES, hydroxylethyl starch; DEX, dextran; Hb, hemoglobin concentration; BV, blood volume; ${ }^{*} p<0.01$ vs. baseline. ${ }^{\S} p<0.01$ vs. hemodilution. ${ }^{\#} p<0.01$ vs. DEX 
Table 3 Changes in renal function from before surgery to POD-1

\begin{tabular}{lllll}
\hline & & Pre-operative & POD-1 & $p$-value \\
\hline $\mathrm{sCre}, \mathrm{mg} / \mathrm{dL}$ & Saviosol & $0.58[0.53,0.65]$ & $0.52[0.47,0.58]$ & $<0.001$ \\
& Voluven & $0.58[0.53,0.62]$ & $0.50[0.47,0.56]$ & $<0.001$ \\
$\mathrm{eGFR}, \mathrm{mL} / \mathrm{kg} / 1.73 \mathrm{~m}^{2}$ & Saviosol & $84.8[73.3,95.3]$ & $94.3[79.5,107]$ & $<0.001$ \\
& Voluven & $81.1[75.6,94.3]$ & $95.9[82.8,109.4]$ & $<0.001$ \\
\hline
\end{tabular}

eGFR estimated glomerular filtration rate, $P O D$ postoperative day, sCre serum creatinine

volume $[17,18]$. The calculated increase in plasma volume without fluid infusion during the induction of anesthesia was $10-15 \%$ [17], corresponding to a 310 to $460 \mathrm{~mL}$ increase in plasma volume. According to the Starling mechanism [19], transcapillary fluid exchange depends on a balance between hydrostatic and oncotic pressure gradients. A reduction of blood pressure induces an acute reduction of the capillary hydrostatic pressure, accompanied by an increase in plasma volume.

Our analyses also revealed that acute hemodilution with $1000 \mathrm{~mL}$ of Voluven increased the patients' $\mathrm{Cl}$ by nearly $5 \mathrm{mmol} / \mathrm{L}$ and decreased their BE by $2 \mathrm{mmol} / \mathrm{L}$, but on POD-1 these changes had not worsened the patients' kidney function. A retrospective study supports our findings; ANH conducted with Voluven ${ }^{\bullet}$ did not increase the incidence of acute kidney injury after major abdominal surgery $(4.8 \%$ vs. $8.0 \%, p=0.20)$, even though ANH induced transient hyper-chloridemia acidosis during surgery [20]. In addition, a randomized controlled trial revealed that balanced 6\% HES 130/0.4 (Tetraspan ${ }^{\circ}$ ) and Voluven ${ }^{\circ}$ showed equal effects for the hemodynamic stabilization of patients undergoing major urologic surgery, without any significant impact on renal function until POD-3 [21]. Additionally, a recent large retrospective study from Japan [22] revealed that the incidence of acute kidney injury was $6.2 \%(548 / 8823)$ in patients receiving Voluven ${ }^{\circ}$ and 5.6\% (492/8823) in controls (OR 1.12; 95\% CI 0.99-1.27; $p=0.07$ ) and Voluven administration was not associated with worsening acute kidney injury stage (OR $0.89 ; 95 \%$ CI $0.79-1.01 ; p=0.08$ ). Interestingly, the incidence of renal replacement therapy was lower in patients receiving Voluven than that in controls $(0.2 \%$ vs $0.4 \%$, respectively; OR $0.51 ; 95 \%$ CI 0.29 $0.91 ; p=0.02)$. These results suggest that transient hyper-chloridemia acidosis is tolerable if volume expansion using colloid solution is well indicated.

A possible mechanism of renal injury-associated hyper-chloridemia is that hyper-chloridemia induces vasoconstriction in afferent arterioles in the kidneys and decreases in renal blood flow and perfusion, thereby causing reductions of the glomerular filtration rate and urine output [23]. Additionally, acidosis may increase the afferent arteriolar resistance in the kidneys. Hyperchloridemia acidosis thus has a potential to reduce renal function. As the clinical impact of infusion-related hyper-chloridemia acidosis has not been fully elucidated, further randomized controlled studies with large sample sizes are required to determine the relationships between infusion-related hyper-chloridemia acidosis and peri-operative renal function and other clinical outcomes of surgical patients.

Our study has some limitations to address. The setting of ANH was not fixed due to a retrospective design. The different setting of ANH could have some impacts on the glycocalyx degeneration and volume status after ANH and, thus, would lead to a bias of the results. In addition, we did not evaluate long-term outcomes including renal function and the survival rate. Further studies with greater numbers of patients are necessary to determine the safety of colloid solutions during ANH in higher-risk patients undergoing major abdominal surgery.

\section{Conclusions}

This retrospective study suggested that the difference in colloid solution during ANH had significant impacts on the volume status, electrolytes, and acid-base balance during surgery for gynecological cancer.

\section{Acknowledgements \\ None.}

Authors' contributions

Y.M. collected data and drafted the manuscript. J.S. designed the study, collected data, performed the statistical analysis, and drafted the manuscript. M.K. designed the study, evaluated the data, and extensively revised the manuscript. K.T. collected data and designed the study. K.H. designed the study, evaluated the data, and extensively revised the manuscript. The authors read and approved the final manuscript and attest to the integrity of the original data and the analysis reported in this manuscript.

\section{Funding}

Not applicable.

\section{Availability of data and materials}

The datasets used and/or analyzed during the current study are available from the corresponding author on reasonable request.

\section{Declarations}

Ethics approval and consent to participate

This study protocol was approved by Hirosaki University's Ethics Committee (2021-039).

Consent for publication

As the study was retrospective, the requirement of patients' written informed consent was waived by the Ethics Committee. 


\section{Competing interests}

All authors except Kazuyoshi Hirota have no competing interests. Kazuyoshi Hirota is one of Editorial Board Members of JA Clinical Reports.

Received: 27 July 2021 Revised: 2 September 2021

Accepted: 2 September 2021 Published online: 13 September 2021

\section{References}

1. Okuno T, Kunisawa S, Fushimi K, Imanaka Y. Intra-operative autologous blood donation for cardiovascular surgeries in Japan: a retrospective cohort study. PLoS One. 2021;16(3):e0247282. https://doi.org/10.1371/journal.pone. 0247282.

2. Henderson RA, Mazzeffi MA, Strauss ER, Williams B, Wipfli C, Dawood M, et al. Impact of intraoperative high-volume autologous blood collection on allogeneic transfusion during and after cardiac surgery: a propensity score matched analysis. Transfusion. 2019;59(6):2023-9. https://doi.org/10.1111/ trf.15253.

3. Saito J, Masui K, Noguchi S, Nakai K, Tamai Y, Midorikawa Y, et al. The efficacy of acute normovolemic hemodilution for preventing perioperative allogeneic blood transfusion in gynecological cancer patients. J Clin Anesth. 2020;60:42-3. https://doi.org/10.1016/j.jclinane.2019.08.025.

4. Kinoshita H, Mikami N, Saito J, Hirota K. Impact of acute normovolemic hemodilution on allogeneic blood transfusion during open abdominal cancer surgery: a propensity matched retrospective study. J Clin Anesth. 2020;64:109822. https://doi.org/10.1016/j.jclinane.2020.109822.

5. Takekawa D, Saito J, Kinoshita H, Hashiba El, Hirai N, Yamazaki Y, et al. Acute normovolemic hemodilution reduced allogeneic blood transfusion without increasing perioperative complications in patients undergoing free-flap reconstruction of the head and neck. J Anesth. 2020;34(2):187-94. https:// doi.org/10.1007/s00540-019-02714-5.

6. Baron DM, Franchini M, Goobie SM, Javidroozi M, Klein AA, Lasocki S, et al. Patient blood management during the COVID-19 pandemic: a narrative review. Anaesthesia. 2020;75(8):1105-13. https://doi.org/10.1111/anae.15095.

7. Velazquez-Kennedy K, Luna A, Sanchez-Tornero A, Jimenez-Chillon C, Jimenez-Martin A, Valles Carboneras A, et al. Transfusion support in COVID19 patients: impact on hospital blood component supply during the outbreak. Transfusion. 2021;61(2):361-7. https://doi.org/10.1111/trf.16171.

8. Ni Y, Xu ZJ, Zhang ZF, Yang C, Liu CM, Gui B. Acute normovolemic hemodilution for major cancer surgeries during the COVID-19 pandemic: a beacon of hope. J Clin Anesth. 2020;65:109871. https://doi.org/10.1016/j. jclinane.2020.109871.

9. Komori M, Samejima Y, Okamura K, Ichikawa J, Kodaka M, Nishiyama K, et al. Effects of crystalloids and colloids on microcirculation, central venous oxygen saturation, and central venous-to-arterial carbon dioxide gap in a rabbit model of hemorrhagic shock. J Anesth. 2019;33(1):108-17. https://doi. org/10.1007/s00540-018-2594-5

10. Smart L, Boyd CJ, Claus MA, Bosio E, Hosgood G, Raisis A. Large-volume crystalloid fluid is associated with increased hyaluronan shedding and inflammation in a canine hemorrhagic shock model. Inflammation. 2018; 41(4):1515-23. https://doi.org/10.1007/s10753-018-0797-4.

11. Nadler SB, Hidalgo JH, Bloch T. Prediction of blood volume in normal human adults. Surgery. 1962:51(2):224-32.

12. Zdolsek HJ, Vegfors $M$, Lindahl TL, Tornquist $T$, Bortnik $P$, Hahn RG. Hydroxyethyl starches and dextran during hip replacement surgery: effects on blood volume and coagulation. Acta Anaesthesiol Scand. 2011:55(6): 677-85. https://doi.org/10.1111/j.1399-6576.2011.02434.x.

13. Löffel LM, Hahn RG, Engel D, Wuethrich PY. Intraoperative Intravascular Effect of Lactated Ringer's Solution and Hyperoncotic Albumin During Hemorrhage in Cystectomy Patients. Anesth Analg. 2021;133(2):413-22 https://doi.org/10.1213/ANE.0000000000005173.

14. Waitzinger J, Bepperling F, Pabst G, Opitz J, Muller M, Francois BJ. Pharmacokinetics and tolerability of a new hydroxyethyl starch (HES) specification [HES (130/0.4)] after single-dose infusion of $6 \%$ or $10 \%$ solutions in healthy volunteers. Clin Drug Investig. 1998;16(2):151-60. https://doi.org/10.2165/00044011-199816020-00008.

15. Klotz U, Kroemer H. Clinical pharmacokinetic considerations in the use of plasma expanders. Clin Pharmacokinet. 1987;12(2):123-35. https://doi.org/1 0.2165/00003088-198712020-00003.

16. Hahn RG, Bergek C, Geback T, Zdolsek J. Interactions between the volume effects of hydroxyethyl starch 130/0.4 and Ringer s acetate. Crit Care. 2013; 17(3):R104. https://doi.org/10.1186/cc12749.
17. Damen T, Reinsfelt B, Redfors B, Nygren A. Pressure-dependent changes in haematocrit and plasma volume during anaesthesia, a randomised clinical trial. Acta Anaesthesiol Scand. 2016;60(5):560-8. https://doi.org/10.1111/aa s.12687.

18. Damen T, Saadati S, Forssell-Aronsson E, Hesse C, Bentzer P, Ricksten SE, et al. Effects of different mean arterial pressure targets on plasma volume, ANP and glycocalyx-a randomized trial. Acta Anaesthesiol Scand. 2021;65(2): 220-7. https://doi.org/10.1111/aas.13710.

19. Starling $\mathrm{EH}$. On the absorption of fluids from the connective tissue spaces. J Physiol. 1896;19(4):312-26. https://doi.org/10.1113/jphysiol.1896.sp000596.

20. Mikami N, Saito J, Ohyama T, Kubota M, Noguchi S, Kitayama M, et al. Acute normovolemic hemodilution and acute kidney injury after open abdominal cancer surgery. J Clin Anesth. 2020;61:109657. https://doi.org/10.1016/j.jclina ne.2019.109657.

21. Helmy A, Mukhtar A, Ahmed A, Sief NE, Hussein A. The intraoperative therapeutic equivalence of balanced vs saline-based $6 \%$ hydroxyethyl starch 130/0.4 and their influence on perioperative acid-base status and renal functions. J Clin Anesth. 2016;32:267-73. https://doi.org/10.1016/j.jclinane.2 016.01.025.

22. Miyao H, Kotake Y. Renal Morbidity of $6 \%$ Hydroxyethyl Starch 130/0.4 in 9000 propensity score matched pairs of surgical patients. Anesth Analg. 2020:130:1618-27.

23. Rein JL, Coca SG. "I don't get no respect": the role of chloride in acute kidney injury. Am J Physiol Renal Physiol. 2019;316(3):F587-605. https://doi. org/10.1152/ajprenal.00130.2018.

\section{Publisher's Note}

Springer Nature remains neutral with regard to jurisdictional claims in published maps and institutional affiliations.

\section{Submit your manuscript to a SpringerOpen ${ }^{\circ}$ journal and benefit from:}

- Convenient online submission

- Rigorous peer review

- Open access: articles freely available online

High visibility within the field

- Retaining the copyright to your article

Submit your next manuscript at $\boldsymbol{\nabla}$ springeropen.com 